\title{
Feeding soyhulls to high-yielding dairy cows increased milk production, but not milking frequency, in an automatic milking system
}

\author{
I. Halachmi, ${ }^{* 1}$ E. Shoshani, $\uparrow$ R. Solomon, $\nmid$ E. Maltz, ${ }^{*}$ and J. Miron* \\ ${ }^{*}$ Agricultural Research Organization (ARO), PO Box 6, Bet Dagan 50250, Israel \\ †Extension Service, Ministry of Agriculture and Rural Development, PO Box 28, Bet Dagan 50250, Israel
}

\begin{abstract}
To attract a cow into an automatic milking system (AMS), a certain amount of concentrate pellets is provided while the cow is being milked. If the milking frequency in an AMS is increased, the intake of concentrate pellets might increase accordingly. Replacing conventional starchy pellets with nonstarchy pellets increased milk yield, milk fat, and milk protein and decreased body weight. The hypothesis was that a nonroughage by-product rich in digestible neutral detergent fiber, such as soyhulls and gluten feed, could replace starchy grain in pellets fed in an AMS. Sixty cows were paired by age, milk yield, and days in milk, and were fed a basic mixture ad libitum $[16.2 \pm 0.35$ (mean $\pm \mathrm{SE}$ ) $\mathrm{kg}$ of dry matter intake/d per cow] plus a pelleted additive (6 to $14 \mathrm{~kg}$ of dry matter/d per cow) that was consumed in the AMS and in a concentrate self-feeder, which could only be entered after passing through the AMS. The 2 feeding regimens differed only in the composition of the pelleted additives: the control group contained $52.9 \%$ starchy grain, whereas the experimental group contained 25\% starchy grain, plus soyhulls and gluten feed as replacement for part of the grain. Wheat bran in the control ration, a source of fiber with low digestibility, was replaced with more digestible soyhulls and gluten. During the first $60 \mathrm{~d}$ in milk, a cow received 10 to $12 \mathrm{~kg}$ of concentrate pellets. After 60 DIM, concentrate feed was allocated by milk production: $\leq 25 \mathrm{~kg} / \mathrm{d}$ of milk entitled a cow to $2 \mathrm{~kg} / \mathrm{d}$ of concentrate feed; $>25 \mathrm{~kg} / \mathrm{d}$ of milk entitled a cow to receive $1 \mathrm{~kg} / \mathrm{d}$ of additional concentrate feed per $5 \mathrm{~kg} / \mathrm{d}$ of additional milk production, and $>60 \mathrm{~kg} / \mathrm{d}$ of milk entitled a cow to receive $9 \mathrm{~kg}$ of concentrate. The concentrate feed was split between the AMS and concentrate self-feeder. The 2 diets resulted in similar frequencies of voluntary milking $(3.12 \pm 0.03$ to 2.65 \pm 0.03 visits $/ \mathrm{d}$ per cow vs. $3.16 \pm 0.00$ to $2.60 \pm 0.01$ visits/d per cow). Average milk yields were higher in
\end{abstract}

Received December 18, 2007.

Accepted December 8, 2008.

${ }^{1}$ Corresponding author: halachmi@volcani.agri.gov.il the experimental group $(42.7 \pm 0.76$ to $39.09 \pm 0.33$ $\mathrm{kg} / \mathrm{d}$ per cow vs. $39.69 \pm 0.68$ to $37.54 \pm 0.40 \mathrm{~kg} / \mathrm{d}$ per cow) and percentages of milk protein $(3.02 \pm 0.06$ to $3.12 \pm 0.05 \%$ vs. $3.07 \pm 0.04$ to $3.20 \pm 0.04 \%)$ and milk fat $(3.42 \pm 0.17$ to $3.44 \pm 0.08 \%$ vs. $3.38 \pm 0.13$ to $3.55 \pm 0.06 \%$ ) were similar in the 2 groups. The results suggest that the proposed pellets high in digestible neutral detergent fiber can be allocated via the AMS to selected high-yielding cows without a negative effect on appetite, milk yield, or milk composition while maintaining a high milking frequency.

Key words: robotic milking, individual feeding, milking frequency, starchy pellet

\section{INTRODUCTION}

During the last $7 \mathrm{yr}$, more than 6,000 milking robots have been sold, mainly in northwestern Europe, Canada, Japan, and Israel, and this increasing use of automatic milking systems (AMS) stimulated the study of pellets in which digestible NDF was substituted for starchy grain. Halachmi et al. (2006) listed several options for inviting a lactating cow to an AMS. The first option involved forced cow-traffic, with a cow being guided to the AMS on her way to or from the forage lane, pasture, or water trough. Nevertheless, studies in the late 1990s (Halachmi, 1999; Ketelaar-De Lauwere et al., 1999) showed that this system could interfere with visits to the forage lane and could reduce the DMI of specific high-yielding cows. Consequently, all AMS farms in Israel were designed around the free cow-traffic concept or they used semiforced traffic, in which the feeding forage lane was always accessible (Halachmi, 2004). This concept was further studied by Hermans et al. (2003) and Melin et al. (2005).

A second option, the "candy concept," used a sweetened feed in the AMS intended to attract the cow. Nevertheless, field tests showed that the cows became accustomed to the sweet taste, so that its attraction declined within a few weeks (Halachmi et al., 2006). The third option was to provide the minimal amount of concentrate pellets at milking that would attract the cows into the AMS (Halachmi et al., 2005). Therefore, 
increased milking frequency in AMS could lead to increased intake of concentrate. Most Israeli AMS use the third option, and cows are usually attracted to the AMS by allocation of no more than $1.2 \mathrm{~kg}$ of feed/milking, which is 4 to $5 \mathrm{~kg} / \mathrm{d}$ of starchy pellets. Unfortunately, this feeding regimen has not been very effective for high-yielding cows $(50$ to $60 \mathrm{~L} / \mathrm{d}$ ) or for encouraging frequent visits to the AMS (Halachmi et al., 2005). In practice, the minimum amount that can be fed in the AMS without adversely affecting voluntary visits of high-yielding cows is as yet unknown (Rodenburg et al., 2004; Halachmi et al., 2005). Increasing the amount of pellets fed in the AMS or in a concentrate self-feeder (CSF) located where cows leave the AMS is desirable to improve the dietary energy balance (Halachmi et al., 2008) and increase visiting frequency (Halachmi, 2009) and milk yield (Halachmi et al., 1998, 2005; Halachmi, 2004). Nevertheless, the increased intake of starchy pellets within a short time could impair the digestibility of dietary NDF and reduce its rate of digestion by ruminal bacteria (Miron et al., 2004a,b). This impaired appetite might reduce the voluntary intake, leading to reduced milk and milk fat production (Miron et al., 2004a). Thus, the supplementation of concentrates in the AMS is a question not only of quantity, but also of milk quality. The current practice is to attract cows to the AMS by using starchy pellets; therefore, high levels of supplementation for high-yielding cows might impair nutritional efficiency.

A fourth option, suggested by Halachmi et al. (2006), was to increase the amount of pellets supplied in the AMS and to change the pellet composition by replacing a starch-rich grain with a by-product higher in digestible NDF. Our present hypothesis was that a nonroughage by-product high in a readily digestible NDF fraction, such as soyhulls (SH) and corn gluten feed, could successfully replace starchy grain in pellets supplied to cows in an AMS by increasing NDF utilization for milk fat production. Under milking parlor conditions, different studies (Ipharraguerre and Clark, 2003; Miron et al., 2004a) demonstrated that when SH was substituted with $35 \%$ of grains in the diet, DMI and milk production were increased. Miron et al. (2004a) suggested that because $\mathrm{SH}$ are higher in fiber content than grains, they might promote chewing, decrease the risk of acidosis and the inhibitory effect of starchy grain on rumen cellulolytic bacteria, promote better NDF digestibility in the rumen, and result in improved health and milk production. Nevertheless, there is a lack of information on the effectiveness of increased allocations of digestible NDF-rich pellets in motivating high-yielding cows to visit an AMS.

The AMS presents a challenge to nutritionists (Halachmi et al., 2006); the TMR concept ceases to be applicable, because a significant amount of the concentrate has to be used as an attractant for visiting the AMS. If a high milking frequency is desired, then a substantial amount of concentrate needs to be provided to prevent frustration among the cows and to maintain a satisfactory milking frequency. However, the provision of a large amount of starchy concentrates to further this process could have negative effects. Moreover, when a TMR is fed, it is possible to include less palatable feedstuffs that have a nutritional economic advantage, but this possibility is limited when a substantial amount of more palatable feed is removed from the mixture. Feeding less palatable concentrates in the AMS incurs the risk of not attracting the cows. Therefore, the objective of the present study was to quantify the effects of replacing starchy grain pellets with pellets high in digestible NDF (6 to $14 \mathrm{~kg} / \mathrm{d}$ per cow) on the AMS behavior of high-yielding cows and on their milking performance.

\section{MATERIALS AND METHODS}

\section{Animals}

The experimental period was 6 mo (October 2006 through March 2007) after a 4-mo basal period. Sixty Israeli Holstein cows milked by AMS were individually paired, matched in lactation number, DIM, milk yield, $\mathrm{BW}$, and visiting frequencies. One cow from each pair was then randomly selected and randomly matched to 1 of the treatment groups, whereas the second cow was placed in the second treatment group. Therefore, the cows were divided randomly into 2 dietary treatment groups of 30 cows each. All the cows were $>10$ DIM when paired and were in at least their second lactation in the AMS; they were familiar with the AMS. Treatment started while some cows were in late lactation, but analysis included only data from calving onward.

\section{Treatments and Diets}

All cows were fed a TMR ad libitum, distributed along the feeding lane, plus a supplement of pelleted additive supplied by dual-channel feeders in the AMS and in the CSF, accessible after passing through the AMS. A significant amount of the concentrate was transferred from the TMR to the AMS. In our case, 14 $\mathrm{kg}$ of concentrates was transferred from the TMR to the AMS (Table 1). The average basic mixture (BM) intake was calculated from the daily weights of BM and of orts left in the feeding lane. Ad libitum intake was kept above 8 to $10 \%$ of the daily amount. Fewer orts were found with an additional amount of BM on successive days. The 2 feeding regimens differed only 
Table 1. Concentrate feed allocation: maximum amounts for both treatment groups

\begin{tabular}{lccc}
\hline DIM & $\begin{array}{c}\text { Automatic } \\
\text { milking system }\end{array}$ & $\begin{array}{c}\text { Self-feeder, } \\
\mathrm{kg} / \mathrm{d} \text { per cow }\end{array}$ & Total \\
\hline $0<$ DIM $<30$ & 5 & 5 & 10 \\
$31<$ DIM & 5 & 7 & 12 \\
$<60$ & 5 & $2-9$ & $7-14$ \\
$61<$ DIM & 4 & 2 & 6 \\
15 d before & & & \\
drying & &
\end{tabular}

in the composition of the pellets fed in the AMS and the CSF: pellets for the control group contained $52.9 \%$ starchy grain, whereas pellets for the experimental group contained $25 \%$ starchy grain plus $\mathrm{SH}$ and gluten feed as grain replacements (Table 2).

The high-starch pellets (control treatment) contained $52.9 \%$ starchy grains and contained the same variety of protein-rich feeds regularly used in Israel, including soybean meal, sunflower meal, corn gluten meal, corn gluten feed, and wheat bran. The experimental pellets contained SH and corn gluten feed in place of part of the starchy grain, and these feeds plus soybean meal were used to replace wheat bran, which is high in medium-digestible NDF (Miron et al., 2001; NRC, 2001). Additional small adjustments in the balance between protein and energy sources were made in the composition of the experimental pellets to achieve similar contents of $\mathrm{CP}(19.1 \%)$ and $\mathrm{NE}_{\mathrm{L}}(1.95 \mathrm{Mcal} / \mathrm{kg}$ of $\mathrm{DM}$ ) in both types of pellets. The BM contained less grain and more roughage than a typical TMR as fed to lactating cows in conventional (non-AMS) Israeli herds; it contained $15.7 \% \mathrm{CP}$ and 1.71 Mcal of $\mathrm{NE}_{\mathrm{L}} / \mathrm{kg}$ of DM. The BM was prepared in a commercial mixing wagon; its composition is shown in Table 3.

The $\mathrm{NE}_{\mathrm{L}}$ values of the individual feeds used were provided by the pellet manufacturers (Zemach Central Feed Mill, Jordan Valley, Israel; Ambar Feed Mill Central Agriculture Cooperative Society Ltd., Hefer, Israel) and were used to summarize $\mathrm{NE}_{\mathrm{L}}$ content of the $\mathrm{BM}$ and the 2 types of pellets.

During the first 2 mo (0 to 60 DIM), each cow received 10 to $12 \mathrm{~kg}$ of concentrate feed (Table 1). Five kilograms of feed was provided in the AMS and the rest was provided in the CSF. After 60 DIM, concentrate feed was allocated according to daily milk production: $25 \mathrm{~L}$ of milk allowed $2 \mathrm{~kg}$ of concentrate feed in the CSF; 25 to $60 \mathrm{~L}$ allowed $1 \mathrm{~kg} / 5 \mathrm{~L}$ of milk; and $60 \mathrm{~L}$ or more

Table 2. Composition of the pellets fed in the automatic milking system (AMS) and in the subsequent concentrate self-feeders (CSF) located behind the AMS, and of the basic mixture served along the feeding lane

\begin{tabular}{lcc}
\hline & \multicolumn{2}{c}{ Dietary treatment $^{1}$} \\
\cline { 2 - 3 } Item & Experimental & Control \\
\hline Basic mixture served, ${ }^{2} \mathrm{~kg}$ of DM/d per cow & 16.2 & 16.2 \\
Pellets fed in the AMS and CSF, kg of DM/d per cow & $6-14$ & $6-14$ \\
Pellet composition, \% of pellet DM & & \\
Ground barley grain & 6.5 & 6.5 \\
Ground corn grain & 18.8 & 34.4 \\
Ground sorghum grain & 7.8 & 7.8 \\
Ground wheat grain & 0 & 5.2 \\
Soyhulls & 30.0 & 0 \\
Corn gluten feed & 9.1 & 9.1 \\
Distillers dried grains & 8.5 & 8.5 \\
Wheat bran & 0 & 9.5 \\
Soybean meal & 7.2 & 7.2 \\
Sunflower meal & 5.6 & 3.5 \\
Gluten meal & 0.67 & 0.67 \\
Canola meal & 0 & 2.0 \\
Protected fat & 2.5 & 2.3 \\
Vitamin + mineral mix ${ }^{3}$ & 3.33 & 3.33 \\
\hline
\end{tabular}

${ }^{1}$ Experimental pellets = pellets containing soyhulls as a replacer for starchy corn and wheat grain and mediumdigestible NDF (wheat bran), served in the AMS plus CSF at a level of 6 to $14 \mathrm{~kg} / \mathrm{d}$ per cow (details in Table 1). Control pellets = pellets containing 52.9\% starchy grain served in the AMS plus CSF at a level of 6 to 14 $\mathrm{kg} / \mathrm{d}$ per cow (details in Table 1 ).

${ }^{2}$ The basic mixture was a mixed ration served for ad libitum intake along the feeding lane to both groups; it contained wheat silage, $325(\mathrm{~kg} /$ ton of DM); clover hay, $125(\mathrm{~kg} /$ ton of DM); oat hay, $20(\mathrm{~kg} / \mathrm{ton}$ of DM); ground corn grains, $210(\mathrm{~kg} /$ ton of DM); and control pellets, $320(\mathrm{~kg} /$ ton of DM).

${ }^{3}$ Vitamin + mineral mix (g/kg of DM pellets): sodium chloride, $5.75 \mathrm{~g}$; calcium chloride, $5.75 \mathrm{~g}$; calcium carbonate, $6.12 \mathrm{~g}$; dicalcium phosphate, $3.75 \mathrm{~g}$; sodium bicarbonate, $9.57 \mathrm{~g}$; trace mineral + vitamin mix, $2.36 \mathrm{~g}$. The trace mineral + vitamin mix contained (g/kg of DM mix) Zn, 24 g; Fe, 24 g; Cu, 12.8 g; Mn, 24 g; I, 1.44 g; Co, 0.32 g; Se, 0.32 g; vitamin A, 16,000,000 IU; vitamin $\mathrm{D}_{3}, 3,200,000$ IU; vitamin E, 48,000 IU. 
Table 3. Chemical composition and in vitro digestibility of the 2 types of pellets fed in the automatic milking system (AMS) and concentrate self-feeder (CSF), and of the basic mixture served along the feeding lane

\begin{tabular}{|c|c|c|c|}
\hline \multirow[b]{2}{*}{ Dietary component, $\%$ of $\mathrm{DM} \pm \mathrm{SD}$} & \multicolumn{2}{|c|}{ Treatment pellets ${ }^{1}$} & \multirow[b]{2}{*}{ Basic mixture } \\
\hline & Experimental & Control & \\
\hline $\mathrm{DM}, \%$ & $89.8 \pm 1.0$ & $88.9 \pm 1.2$ & $64.1 \pm 1.1$ \\
\hline OM, \% & $95.6 \pm 1.1$ & $95.6 \pm 1.1$ & $91.5 \pm 1.6$ \\
\hline $\mathrm{CP}$ & $19.1 \pm 0.1$ & $19.1 \pm 0.1$ & $15.7 \pm 0.2$ \\
\hline NDF from roughage & - & - & $24.7 \pm 0.2$ \\
\hline Total NDF & $28.5 \pm 1.1$ & $22.1 \pm 1.2$ & $34.2 \pm 1.4$ \\
\hline Fat & $7.1 \pm 0.2$ & $6.5 \pm 0.1$ & $4.0 \pm 0.1$ \\
\hline Starch and soluble carbohydrate ${ }^{3}$ & 40.9 & 47.9 & 37.6 \\
\hline Calculated $\mathrm{NE}_{\mathrm{L}}, \mathrm{Mcal} / \mathrm{kg}$ of $\mathrm{DM}$ & 1.95 & 1.95 & 1.71 \\
\hline \multicolumn{4}{|l|}{ In vitro digestibility, $\%$} \\
\hline DM & $81.3^{\mathrm{a}}$ & $82.4^{\mathrm{a}}$ & $74.2^{\mathrm{b}}$ \\
\hline NDF & $76.8^{\mathrm{a}}$ & $66.1^{\mathrm{b}}$ & $63.3^{\mathrm{b}}$ \\
\hline
\end{tabular}

${ }^{\mathrm{a}, \mathrm{b}}$ Means in the same row with different superscripts differ at $P<0.05$.

${ }^{1}$ Experimental pellets $=$ pellets containing soyhulls and gluten feed as a replacer for starchy grain and mediumdigestible NDF, served in the AMS plus CSF at a level of 6 to $14 \mathrm{~kg} / \mathrm{d}$ per cow. Control pellets = pellets containing 52.9\% starchy grain served in the AMS plus CSF at a level of 6 to $14 \mathrm{~kg} / \mathrm{d}$ per cow.

${ }^{2}$ Basic mixture $=$ mixed ration served for ad libitum intake along the feeding lane to both groups at a maximal level of $16.2 \mathrm{~kg}$ of $\mathrm{DM} / \mathrm{d}$ per cow.

${ }^{3}$ Starch and soluble carbohydrate content were calculated as follows: Starch + Soluble carbohydrate $\%=$ OM $\%$ $-\mathrm{CP} \%-\mathrm{NDF} \%$ - Fat\%.

allowed $9 \mathrm{~kg}$ in addition to the $5 \mathrm{~kg}$ in the AMS. The maximum amount of pellets fed via the AMS and the CSF was up to $14 \mathrm{~kg} / \mathrm{d}$ per cow (approximately $50 \%$ of daily DMI). The minimum amount of concentrate in the AMS was held constant at $5 \mathrm{~kg} / \mathrm{d}$ because this material filled the role of keeping the cow eating throughout the milking process. The pellets were allocated for entire days under the practice of linear accumulation of the feed allowance: for example, a cow that was allowed 7 $\mathrm{kg} / \mathrm{d}$ of pellets, and those that had not visited the AMS for $10 \mathrm{~h}$ would receive $(7 / 24) \times 10=2.9 \mathrm{~kg}$. In setting the AMS parameters, the number of feed cycles was set to 24 and the number of feed periods was set to 1 . The amount of pellets per meal ranged from 1 to $3 \mathrm{~kg}$. The CSF dispenser was calibrated to provide $300 \mathrm{~g} /$ min, and the AMS feed rate was $250 \mathrm{~g} / \mathrm{min}$. Allocated feed that was not consumed was transferred to the next day's allocation; up to $4 \mathrm{~kg}$ could be transferred, and the transfer operation was designated as "add balance $=4 \mathrm{~kg}$ " in the AMS management software.

\section{Management}

All the cows were kept together in a single pen. Individual cows could be recognized only by their associated feeding parameters in the management software. Thus, both the control and experimental groups were exposed to identical conditions, housing and microclimate in the barn, management practices, and cow handling by the workers, and the same AMS was shared by both groups. The barn was designed to enable cows to move freely between the BM feeding lane and resting areas. Cows visited the AMS voluntarily but could access the CSF only after passing through the milking stall; they were motivated to visit the AMS because that was their only way of accessing the pellets, either in the AMS or in the CSF. Halachmi et al. (1998, 2000a,b) coined the phrase "semiforced cow-traffic" to describe this situation. The maximum milking frequency of any cow, specified in the AMS software, was 5 times per day. The barn was designed to hold 65 to 75 cows in milking, with approximately $20 \mathrm{~m}^{2} /$ cow, and was equipped with a cow cooling system near the AMS. Every day at $0600 \mathrm{~h}$, the BM was distributed by a mixer wagon. At $0530 \mathrm{~h}$ and again between 1200 and $1300 \mathrm{~h}$ each day, the farm workers led in the few cows (2 or 3 cows) that had not visited the AMS for more than $8 \mathrm{~h}$. The AMS utilization during the experimental period was less than $83 \%$, to allow cows with low social rank to visit a milking stall without the need to fight their way to the AMS.

\section{Facilities, Sampling, Chemical Analyses, and In Vitro Digestibility Measurements}

The AMS and the CSF are products of the Lely Industry (Maasland, the Netherlands). Each was equipped with 2 feeding channels ( 1 for the control pellets and 1 for the experimental pellets), an electronic identification instrument, and computerized control and recording of the entry of cows into the feed stalls. All of these features enabled monitoring of pellet intake by individual cows in the group. Both the control and 
experimental pellets were allocated at the same rates of $250 \mathrm{~g} / \mathrm{min}$ in the AMS and $300 \mathrm{~g} / \mathrm{min}$ in the CSF; they were calibrated weekly and whenever a new batch of concentrates was delivered. The cows were free to eat the BM anywhere along the feeding lane.

The BM and both kinds of pellets were sampled weekly. A part of the weekly sample was assayed in triplicate for DM content (drying at $105^{\circ} \mathrm{C}$ for $24 \mathrm{~h}$ ) and ash $\left(4 \mathrm{~h}\right.$ at $\left.600^{\circ} \mathrm{C}\right)$; other dry samples $\left(60^{\circ} \mathrm{C}\right.$ oven for $96 \mathrm{~h}$ ) were analyzed for $\mathrm{CP}$ according to the Kjeldahl method (AOAC, 2000) and cell wall components. Neutral detergent fiber, ADF, and acid detergent lignin were determined by sequential analysis, without sodium sulfite, with heat-stable amylase, and were expressed exclusive of residual ash (van Soest et al., 1991). An Ankom 220 apparatus (Ankom, Fairport, NY) was used for extraction and filtering.

In vitro digestibility of DM and NDF of the BM and of the pellets was determined in triplicate for each sample. The procedure included a 48-h incubation of $0.5 \mathrm{~g}$ of plant material with rumen fluid, followed by a 48-h incubation with $\mathrm{HCl}$ and pepsin, according to the 2-stage fermentation technique of Tilley and Terry (1963).

Milk yield was recorded by automatic milk meters in the AMS. Milk samples were collected over $24 \mathrm{~h}$ (2 to 5 sequential milkings of each cow) at 2-wk intervals during the experimental period. Each set of milk samples from each cow was stored at $4^{\circ} \mathrm{C}$ in the presence of preservative bromide compounds pending infrared analysis for contents of fat, protein, lactose, and urea (AOAC, 2000), with a MilkoScan 4000 instrument (Foss Electric, Hillerød, Denmark).

\section{Calculations and Statistical Analyses}

All milk-recording samples were taken into account (repeated measurement). The daily yield per cow of $4 \%$ FCM and the payment equation to determine economically corrected milk (EcCM) were calculated according to the practice of the Israeli Cattle Breeders Association:

$$
\begin{aligned}
4 \% \mathrm{FCM} & (\mathrm{kg})=0.4 \times \text { milk }(\mathrm{kg})+15.0 \\
& \times \text { milk fat }(\mathrm{kg}), \text { and } \\
\mathrm{EcCM}(\mathrm{kg}) & =9.436 \times \text { milk fat }(\mathrm{kg})+22.018 \\
& \times \text { milk protein }(\mathrm{kg}) .
\end{aligned}
$$

The data were organized with Statistics Toolbox software (MatLab; Mathworks, 1999). Statistical analyses were performed with the general linear model procedure (SAS Institute, 1996):

$$
\begin{aligned}
\mathrm{Y}_{\mathrm{ijk} \mathrm{k}}=\mathrm{A}_{\mathrm{i}} & +\mathrm{B}_{\mathrm{j}}\left(\mathrm{A}_{\mathrm{i}}\right)+\mathrm{C}_{\mathrm{k}}+\left(\mathrm{A}_{\mathrm{i}} \times \mathrm{C}_{\mathrm{k}}\right)+\mathrm{DIM} \\
& +\mathrm{DIM}^{2}+\mathrm{DIM}^{3}+\mathrm{e}_{\mathrm{ijk} \mathrm{k}},
\end{aligned}
$$

where $\mathrm{Y}_{\mathrm{ijkl}}$ is milk, EcCM, or fat or protein percentage; $A_{i}$ is the control vs. experimental group; $B_{j}\left(A_{i}\right)$ is cow nested within a group; $\mathrm{C}_{\mathrm{k}}$ is stage of lactation; ( $\mathrm{Ai} \times$ $\mathrm{C}_{\mathrm{k}}$ ) is the treatment $\times$ stage of lactation interaction; $\operatorname{DIM}\left(10,60\right.$ d), $\operatorname{DIM}^{2}$ (61, 120 d), and $\operatorname{DIM}^{3}$ (121, 180 d) are the DIM linear, quadratic, and cubic terms; and $\mathrm{e}_{\mathrm{ijkl}}$ is the error term.

\section{RESULTS AND DISCUSSION}

The milk yield of the experimental group was higher than that of the control group throughout the lactation (Figure 1 and Table 4). No significant differences were recorded in concentrate feed intake (Table 5), willingness to consume pellets (Table 6 ), or milking frequency (Figure 2 and Table 7).

The higher milk yield could have been caused by the following: 1) consumption of the $\mathrm{BM}$ was higher at the feeding lane, which would be consistent with the findings of Bach et al. (2007); 2) because SH are higher in fiber content than grains, it may have promoted chewing, thereby decreasing the risk of acidosis and the inhibitory effect of starchy grain on rumen cellulolytic bacteria and resulting in improved digestibility of the NDF fraction in the BM ingested because of the improved conditions created in the rumen (Miron et al., 2004a); 3) SH maintained the high intake of energy and nutrients from the pellets, supporting high milk production; and 4) the allocation of nutrients to BW gain was decreased (Table 8). Nutritional values of SH to support milk production and rumen health and metabolism are well known (Ipharraguerre and Clark, 2003; Miron et al., 2004a,b). Soyhulls contain approximately $60 \%$ NDF originating from the primary cell wall, which is highly digestible (Miron et al., 2001). Soyhulls contain nearly 3 times more lysine and methionine (both rate-limiting AA for milk production) than corn grain. In contrast, wheat bran added to the control diets $(\sim 9.1 \%)$ contained approximately $50 \%$ NDF; however, its NDF polysaccharides were less digestible in the rumen than SH NDF carbohydrate (Miron et al., 2001). Further research, within the context of the AMS, barn design, and method of feed, is warranted.

Table 5 shows that cows in both treatments consumed similar amounts of concentrate feed. The cows actually consumed approximately 85 to $92 \%$ (Table 6) of the allocated feed; their feed consumption declined slightly in the course of the lactation, from 92 to $85 \%$ of the control pellets and from 88 to $85 \%$ of the experimental pellets. 
Table 4. Milk yield and milk composition

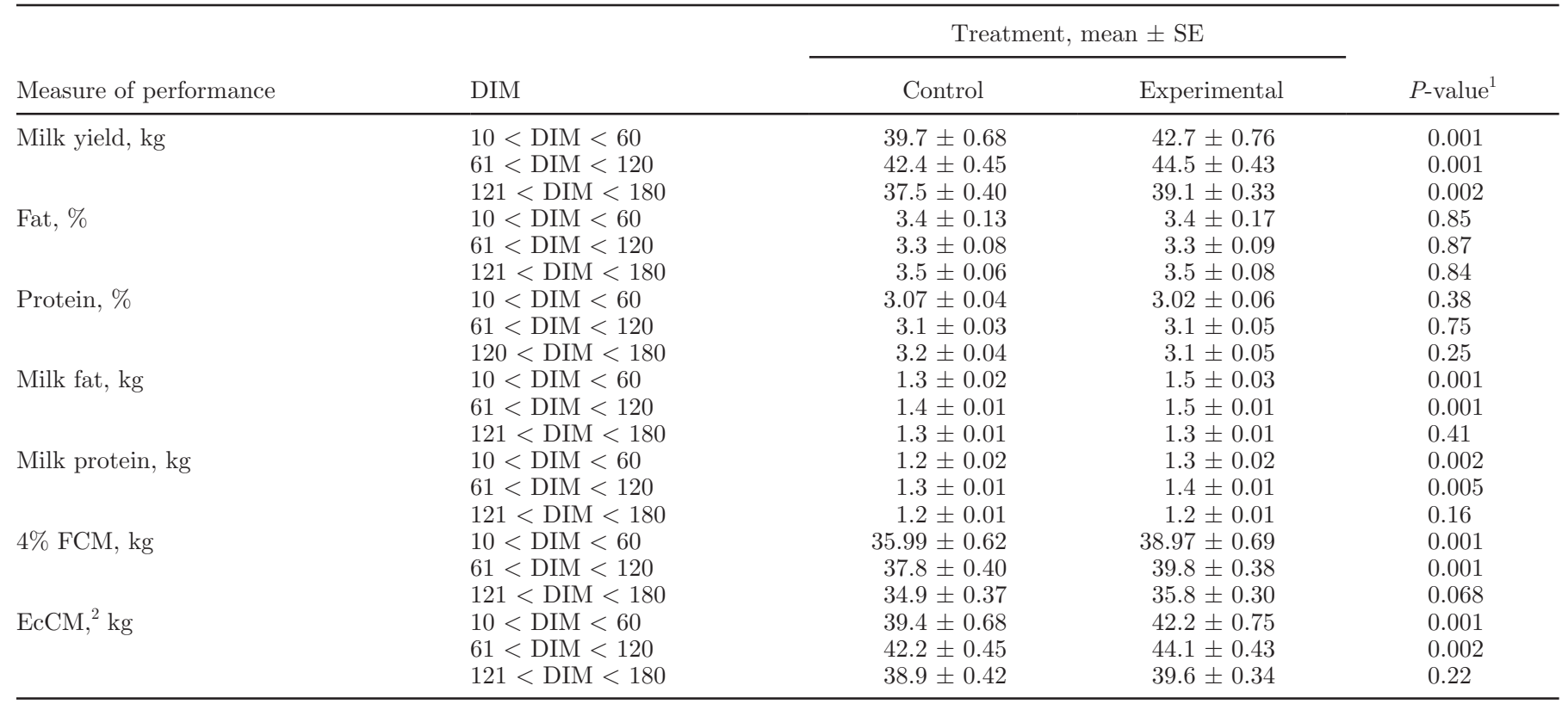

${ }^{1}$ Not significant, $P \geq 0.05$.

${ }^{2}$ Economically corrected milk (EcCM) was calculated according to the practice of the Israeli Cattle Breeders Association: EcCM (kg) $=9.436$ $\times$ milk fat $(\mathrm{kg})+22.018 \times$ milk protein $(\mathrm{kg})$.

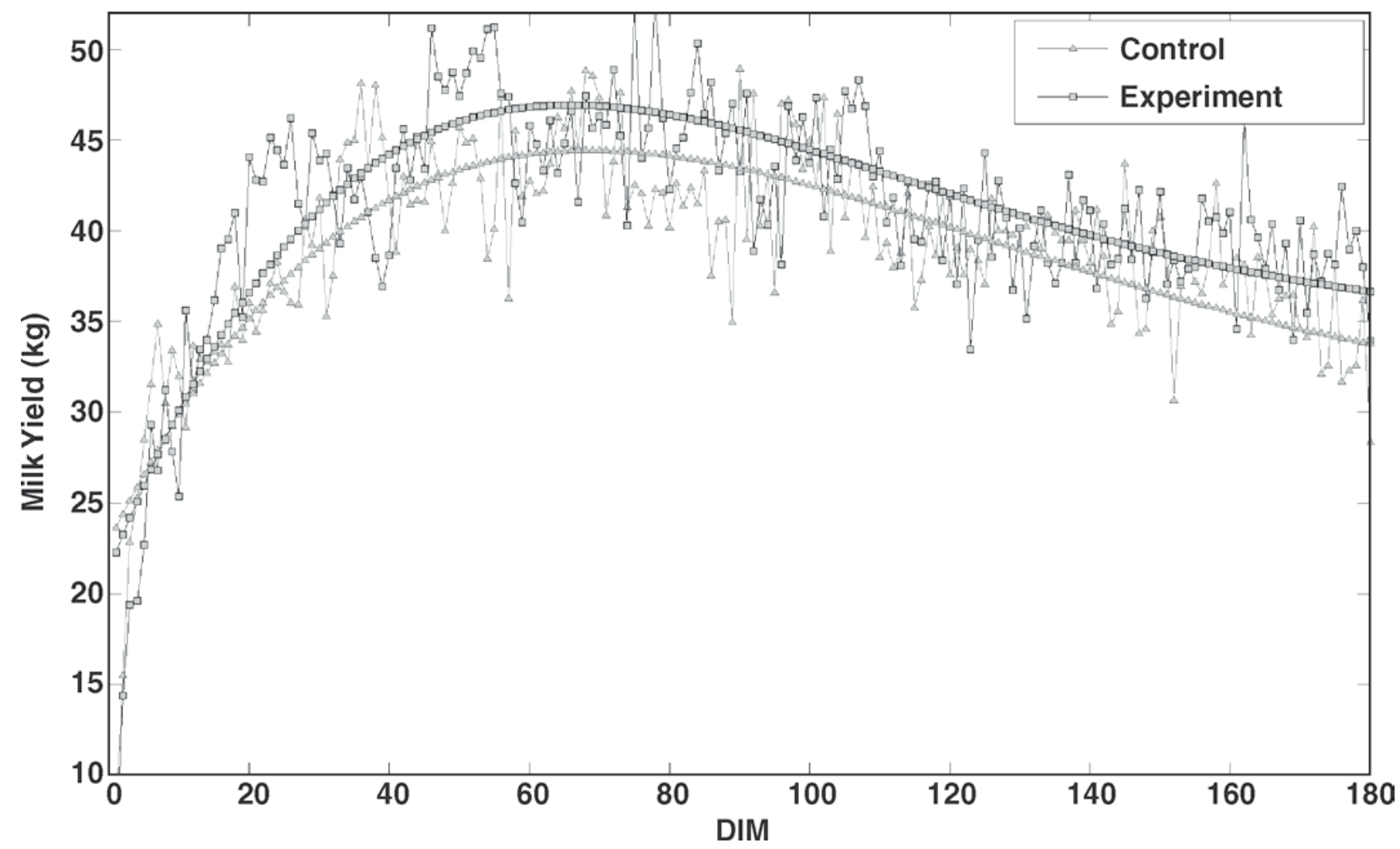

Figure 1. Milk yield (kg/d per cow) over DIM in the experimental (squares) and control (triangles) treatments. Lines represent trend lines. The trend lines were calculated by the smoothing algorithm of Whittaker (1923). Third-order differences and $\lambda=10,000$ were implemented. Detailed equations of the algorithm of Whittaker (1923) are presented in the appendix of Halachmi et al. (2004). 


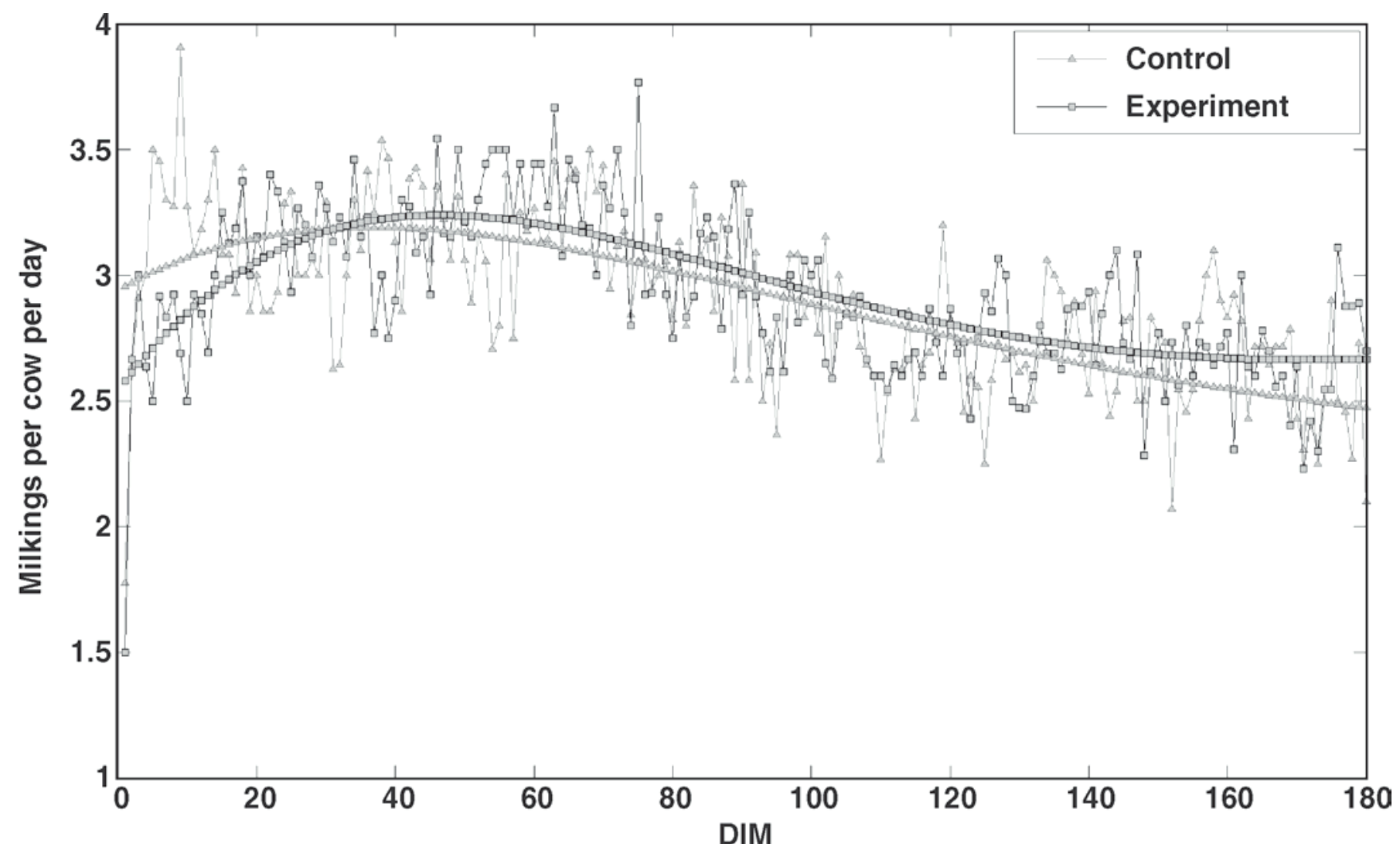

Figure 2. Number of voluntary milkings over DIM in the experimental (squares) and control (triangles) treatments. Lines represent trend lines (Whittaker, 1923; Halachmi et al., 2004).

Table 7 shows the voluntary milking frequency during lactation; no significant difference between treatments was observed. This finding suggests there is no clear research evidence supporting the common speculation that starchy grain makes cows lazy and unwilling to attend the AMS for milking (Halachmi et al., 2005).

No abnormal health incidences and no deaths were reported, yet a difference in BW developed in the later stages of lactation (Table 8). Cows in the experimental group collectively lost between $960 \mathrm{~kg}[(619-587) \mathrm{kg}$ $\times 30$ cows $=960 \mathrm{~kg}]$ and $870 \mathrm{~kg}$ of BW by the end of the experiment. Cows in the experimental group collectively produced an additional $198.6 \mathrm{~kg}$ of milk by the

Table 5. Cow feed intake in the automatic milking system and concentrate self-feeder (pellet intake, $\mathrm{kg} / \mathrm{d}$ per cow)

\begin{tabular}{lccc}
\hline & \multicolumn{2}{c}{ Treatment, mean \pm SE } & \\
\cline { 2 - 3 } DIM & Control & Experimental & \\
\hline -value & \\
\hline $10<$ DIM $<60$ & $10.2 \pm 0.39$ & $10.2 \pm 0.46$ & 0.97 \\
$61<$ DIM $<120$ & $10.8 \pm 0.46$ & $11.4 \pm 0.44$ & 0.16 \\
$120<$ DIM $<180$ & $10.0 \pm 0.39$ & $10.8 \pm 0.42$ & 0.09 \\
\hline
\end{tabular}

${ }^{1} P \geq 0.05$. end of the experiment. This weight loss is an average $4.38 \mathrm{~kg}$ of BW per production of $1 \mathrm{~kg}$ of milk. The cows lost their BW during mid lactation.

\section{Comparison with Previous Publications}

Halachmi et al. (2005), who used starchy grains and compared the effects of allocating 1.5 or $7 \mathrm{~kg} / \mathrm{d}$ of concentrate per cow at the AMS, found no differences in milking attendance. When Halachmi et al. (2006) compared starchy grains with pellets rich in digestible $\mathrm{NDF}$, they found that for concentrate allocations up to $5.5 \mathrm{~kg} / \mathrm{d}$ per cow, the incentive offered by the provision

Table 6. Ratio of concentrate feed eaten and allocated pellets (actual intake per planned allocation ratio)

\begin{tabular}{lccc}
\hline & \multicolumn{2}{c}{ Treatment, mean $\pm \mathrm{SE}$} & \\
\cline { 2 - 3 } DIM & Control & Experimental & \\
\hline 10 -value \\
\hline $1<$ DIM $<60$ & $0.92 \pm 0.20$ & $0.88 \pm 0.17$ & 0.28 \\
$120<$ DIM $<120$ & $0.89 \pm 0.14$ & $0.89 \pm 0.15$ & 0.85 \\
\hline
\end{tabular}

${ }^{1}$ Not significant, $P \geq 0.05$. 
Table 7. Number of voluntary milkings/day per cow in cows fed 2 different diets in an automatic milking system

\begin{tabular}{lccc}
\hline \multirow{2}{*}{ DIM } & \multicolumn{2}{c}{ Treatment, mean $\pm \mathrm{SE}$} & \\
\cline { 2 - 3 } & Control & Experimental & $P_{\text {-value }}$ \\
\hline $10<\mathrm{DIM}<60$ & $3.12 \pm 0.03$ & $3.16 \pm 0.00$ & 0.33 \\
$61<\mathrm{DIM}<120$ & $2.95 \pm 0.04$ & $2.95 \pm 0.01$ & 0.48 \\
$120<\mathrm{DIM}<180$ & $2.65 \pm 0.03$ & $2.60 \pm 0.01$ & 0.20 \\
\hline
\end{tabular}

${ }^{1} P \geq 0.05$.

of concentrate at an AMS was independent of the starch content of the grain; therefore, the possibility of feeding large amounts of concentrate at the AMS without causing rumen acidosis seemed realistic. They found no significant difference in milk yield (35.4 vs. $35.8 \mathrm{~kg} / \mathrm{d}$ per cow). More recently, Bach et al. (2007) tried this approach and compared concentrate allocations of up to $3 \mathrm{~kg} / \mathrm{d}$ per cow in the AMS with $8 \mathrm{~kg} / \mathrm{d}$ per cow, but found no evidence of a stimulating effect. In addition, they found no differences in attendance at an AMS. In the present study, the concentrate allocation reached 14 $\mathrm{kg} / \mathrm{d}$, and a significant difference in milk yield favored the experimental group.

\section{Pellets High in Digestible NDF Versus Starchy Pellets in the AMS}

Pellets rich in digestible NDF had advantages over starchy pellets for milk fat and FCM production in milking parlor-oriented farms (Miron et al., 2004a; Zenou and Miron, 2005). However, a reduction in milk fat content was obtained in cows that were fed BM along the feeding lane and starchy pellets in the TMR, as compared with that obtained under a conventional TMR feeding regimen (Miron et al., 2004a).

The present study showed that the experimental pellets that formed up to $21 \%$ of dietary DM were sufficiently attractive to make their voluntary intake similar to that of conventional starchy pellets. The experimental pellets enhanced FCM and EcCM production. Thus, the experimental pellets can be supplied as an alternative to starchy pellets in an AMS in cases in which increased milk fat production is desirable. Substitution

Table 8. Cow BW $(\mathrm{kg})$ during lactation in cows fed 2 different diets in an automatic milking system

\begin{tabular}{lccc}
\hline & \multicolumn{2}{c}{ Treatment, mean $\pm \mathrm{SE}$} & \\
\cline { 2 - 3 } DIM & Control & Experimental & $P$-value \\
\hline $10<\mathrm{DIM}<60$ & $573.8 \pm 10.2$ & $573.2 \pm 10.8$ & 0.96 \\
$61<\mathrm{DIM}<120$ & $619 \pm 8.21$ & $587 \pm 6.7$ & 0.001 \\
$120<\mathrm{DIM}<180$ & $608 \pm 10.6$ & $579 \pm 6.4$ & 0.005 \\
\hline
\end{tabular}

of conventional starchy pellets fed at early lactation with pellets rich in digestible NDF led to more milk, but not to a greater frequency of milking in the AMS.

\section{CONCLUSIONS}

The inclusion of SH pellets high in digestible NDF in place of starchy grains fed to high-yielding dairy cows milked in an AMS 1) led to more milk, but not to a greater frequency of milking in the AMS; and 2) led to an increase in daily milk yields from 39.7 to $42.7 \mathrm{~kg}$ at 10 to $60 \mathrm{DIM}$, from 42.4 to $44.4 \mathrm{~kg}$ at 61 to $120 \mathrm{DIM}$, and from 37.54 to $39.09 \mathrm{~kg}$ at 120 to 180 DIM. This study adds evidence showing that what is fed in the AMS has no impact on milking frequency.

\section{ACKNOWLEDGMENTS}

The study was financed by the Israeli Cattle Breeding Association, project number 459-0389-04. The authors acknowledge the assistance provided by the dairy farm staff Noam Kremer, Gilad Kremer, and Rami Kremer, and ARO technician Aharon Antler. Special thanks are due to the farm nutritionists and feed suppliers, the late Catriel Tavori of Zemach Industries, and Lior Kesary and Shimon Ofir of Ambar Feed Mills. Thanks are due to Ofer Krol for fruitful discussions and critical comments.

\section{REFERENCES}

AOAC. 2000. Official Methods of Analysis. 17th ed. Assoc. Off. Anal. Chem., Gaithersburg, MD.

Bach, A., C. Iglesias, S. Calsamiglia, and M. Devant. 2007. Effect of amount of concentrate offered in automatic milking systems on milking frequency, feeding behavior, and milk production of dairy cattle consuming high amounts of corn silage. J. Dairy Sci. 90:5049-5055.

Halachmi, I. 1999. Designing the optimal robotic barn, Part 2: Behaviour-based simulation. J. Agric. Eng. Res. 77:67-79.

Halachmi, I. 2004. Designing the automatic milking farm in a hot climate. J. Dairy Sci. 87:764-775.

Halachmi, I. 2009. Simulating the hierarchical order and cow queue length in an automatic milking system. Biosyst. Eng. (accepted)

Halachmi, I., I. J. B. F. Adan, J. van der Wal, J. A. P. Heesterbeek, and P. van Beek. 2000a. The design of robotic dairy barns using closed queuing networks. Eur. J. Oper. Res. 124:437-446.

Halachmi, I., Y. Edan, U. Moallem, and E. Maltz. 2004. Predicting feed intake of the individual dairy cow. J. Dairy Sci. 87:2254-2267.

Halachmi, I., J. A. P. Heesterbeek, and J. H. M. Metz. 1998. Designing the optimal robotic milking barn, using simulation. Pages 13-17 in Dutch-Japanese Workshop on Precision Dairy Farming. Wageningen University Press, Wageningen, the Netherlands.

Halachmi, I., J. H. M. Metz, E. Maltz, A. A. Dijkhuizen, and L. Speelman. 2000b. Designing the optimal robotic barn, Part 1: Quantifying facility usage. J. Agric. Eng. Res. 76:37-49.

Halachmi, I., S. Ofir, and J. Miron. 2005. Comparing two concentrate allowances in an automatic milking system. Anim. Sci. 80:339344.

Halachmi, I., P. Polak, D. Roberts, and M. Klopcic. 2008. Cow body shape and automation of condition scoring. J. Dairy Sci. 91:44444451 . 
Halachmi, I., E. Shoshani, R. Solomon, E. Maltz, and J. Miron. 2006. Feeding of pellets rich in digestible neutral detergent fiber to lactating cows in an automatic milking system. J. Dairy Sci. 89:3241-3249.

Hermans, G. G. N., A. H. Ipema, J. Stefanowska, and J. H. M. Metz. 2003. The effect of two traffic situations on the behavior and performance of cows in an automatic milking system. J. Dairy Sci. 86:1997-2004.

Ipharraguerre, I. R., and J. H. Clark. 2003. Soyhulls as alternative feed for lactating cows. J. Dairy Sci. 86:1052-1073.

Ketelaar-De Lauwere, C. C., A. H. Ipema, J. H. M. Metz, J. P. T. M. Noordhuizen, and W. G. P. Schouten. 1999. The influence of the accessibility of concentrate on the behaviour of cows milked in an automatic milking system. Neth. J. Agric. Sci. 47:1-16.

Mathworks. 1999, Statistics toolbox. MatLab User's Guide. The Mathworks Inc., Natick, MA.

Melin, M., H. Wiktorsson, and L. Norell. 2005. Analysis of feeding and drinking patterns of dairy cows in two cow traffic situations in automatic milking systems. J. Dairy Sci. 88:71-85.

Miron, J., M. Nikbachat, A. Zenou, D. Ben-Ghedalia, R. Solomon, E. Shoshani, I. Halachmi, N. Livshin, A. Antler, and E. Maltz. 2004b. Lactation performance and feeding behavior of dairy cows supplemented via automatic feeders with soy hulls or barley based pellets. J. Dairy Sci. 87:3808-3815.

Miron, J., E. Yosef, and D. Ben-Ghedalia. 2001. Composition and in vitro digestibility of monosaccharide constituents of selected byproduct feeds. J. Agric. Food Chem. 49:2322-2326.
Miron, J., E. Yosef, M. Nikbachat, A. Zenou, E. Maltz, I. Halachmi, and D. Ben-Ghedalia. 2004a. Feeding behavior and performance of dairy cows fed pelleted non-roughage fiber byproducts. J. Dairy Sci. $87: 1372-1379$.

NRC. 2001. Nutrient Requirements of Dairy Cattle. 7th ed. Natl. Acad. Press, Washington, DC.

Rodenburg, J., E. Focker, and K. Hand. 2004. Effect of the composition of concentrate fed in the milking box on milking frequency and voluntary attendance in automatic milking systems. Pages 511-512 in A Better Understanding of Automatic Milking. A. Meijering, H. Hogeveen, and C. J. A. M de Koning, ed. Wageningen Academic Publishers, Wageningen, the Netherlands.

SAS Institute. 1996. SAS User's Guide: Statistics. Version 6.12. SAS Inst. Inc., Cary, NC.

Tilley, J. M., and R. M. Terry. 1963. A two stage technique for the in vitro digestion of forage crops. J. Br. Grassl. Soc. 18:104-111.

van Soest, P. J., J. B. Robertson, and B. A. Lewis. 1991. Methods for dietary fiber, neutral detergent fiber, and non-starch polysaccharides in relation to animal nutrition. J. Dairy Sci. 74:3583-3597.

Whittaker, E. T. 1923. On a new method of graduation. Proc. Edinb. Math. Soc. 41:63-75.

Zenou, A., and J. Miron. 2005. Milking performance of dairy ewes fed pellets containing soy hulls as starchy grain substitute. Small Rumin. Res. 57:187-192. 